\title{
Lime treated soil erodibility investigated by EFA erosion testing
}

\author{
A. Bennabi \\ IRC - ESTP-Paris - COMUE Paris Est, 28, Avenue du Président Wilson, 94230 Cachan
}

G. Herrier, D. Lesueur

LHOIST Recherche et Développement, 31 Rue de l'industrie, B 1400 Nivelles

\begin{abstract}
Erosion is susceptible to reduce the overall stability of a structure under hydraulic and static loads, but also can lead to the development of a fast breach. In parallel, dikes and levees builders and designers have not so many ways to improve initial properties of materials available on site, for the construction or restoration of hydraulic embankments. In this context, soil treatment with lime is a relevant procedure that is reported to improve the mechanical properties and erosion behavior of silty and clayey soils.

This study focuses on the changes induced by lime treatment on the erosion resistance of a silty soil, and the evolution of relevant erosion parameters with curing time. EFA (Erosion Function Apparatus) tests on a silty soil from Marche-les-Dames (Belgium) were performed on the native soil, and after $2.5 \%$ lime addition at several curing times (1, 7 and 28 days). After 1 day curing time, a slight increase in the soil erosion resistance is recorded, whereas after seven days submitted to a water flow velocity above $3 \mathrm{~m} / \mathrm{s}$, the soil passes from a medium to a low erodibility level. After 28 days, the soil has a very low erodibility for the same water velocity.
\end{abstract}

\section{NTRODUCTION}

There are $9000 \mathrm{~km}$ of dikes against flooding and $6700 \mathrm{~km}$ waterway dams in France. Breaks over fifty small dams that can be attributed to erosion, which about half of them by overflow, were reported in France (Bonelli, 2012).

A study of Foster et al. (2000), based on 11192 hydraulic works, showed that 136 of them underwent disorders: $6 \%$ slip, $46 \%$ by internal erosion and $48 \%$ by overflow.

These figures explain the interest in research undertaken in many countries to better understand the phenomena associated with internal erosion and to find solutions to limit their occurrence.

Lime treatment of soils has long been a technique used to improve the engineering properties of soils, in particular when they do not have the required characteristics to make them suitable for acting as foundations for infrastructures such as roads, railways or logistic platforms. It can also be used to stabilize the bases or subbases of these infrastructures. This technique, already used in many countries worldwide, with well documented experience in countries such as USA and France, only begins to be investigated in order to improve the resistance of soils to erosion. In this sense, an extensive research program started in 2005 by the Lhoist Group, a world-leading lime producer, helped identify the rel- evant conditions and the lime treatment procedures that are appropriate for using lime-treated soils in hydraulic structures (Herrier et al. 2014). This research also documented the relevant properties of lime-treated soils for use in hydraulic earthen works in contact with water, as highlighted by the building of a full-scale lime-treated dike. In this real scale experiment, it was possible to compare not only treated and untreated soils, but also laboratory results to insitu measurements, showing the promising potential of the technology. A study on sandy soils of volcanic ash treated with lime (Awad et al. 2007) focused on the prediction of the rate of soil loss due to overflow erosion and its relationship with the peak compressive strength. The study notably highlighted the need to take into account the spatial variability of parameters such as the degree of compaction, moisture content and particle size distribution of the soil to be able to make realistic predictions of overflow erosion.

This paper presents the results of a study carried out in the framework of a partnership between ESTP Paris and Lhoist Company which consisted in the comparison of external erosion resistance of soils without and with lime treatment, and assessing the development of resistance to erosion of lime treated soil with lime. 


\section{EXPERIMENTAL INVESTIGATION}

\subsection{Properties of soil and lime used in the testing programme}

The soil is the overburden material coming from the Marche-les-Dames quarry (Belgium). The characteristics of this silty soil having a low plasticity index, are summarized in Table 1. This same soil was used to build the already mentioned real-scale experimental dikes with and without lime treatment, from which mechanical and hydraulic characteristics of materials were assessed. The results of this experience can be found in (Charles et al. 2014), and are completed with the present EFA test results.

Table 1. Identification characteristics of the silty soil from Marches-les-Dames (Belgium)

\begin{tabular}{ll}
\hline Clay fraction $(<2 \mu \mathrm{m})$ & 12 \\
\hline Silt fraction $(2$ to $50 \mu \mathrm{m})$ & 82 \\
\hline Passing through $80 \mu \mathrm{m}$ sieve & 99.5 \\
\hline Methylene Blue Value $(\mathrm{g} / 100 \mathrm{~g})$ & 2.5 \\
\hline Plasticity index & 7 to 8 \\
\hline Moisture content at sampling & 17.9 \\
\hline
\end{tabular}

The lime used for the soil treatment is a Proviacal ( as CL 90-Q quick lime according to EN 459-1 standard. It contains $90.9 \%$ of available $\mathrm{CaO}$ and reactivity $\left(\mathrm{t}_{60}\right)$ of 3.3 minutes.

The changes induced by the lime treatment on the compaction behavior of the soil are illustrated in Fig. 1. The optimal moisture content for Standard Proctor compaction of untreated soil is $\mathrm{w}_{\mathrm{OMC}}=14.5 \%$ and the corresponding dry density is $\gamma_{\mathrm{d}}=18.2 \mathrm{kN} / \mathrm{m}^{3}$. It is known that lime treatment leads to a displacement of the $\mathrm{w}_{\text {OMC }}$ towards higher moisture contents and a reduction of the maximal dry density: the specific compaction characteristics of the Marche-les-Dames silty soil treated with $2.5 \%$ quicklime are $\gamma_{\mathrm{d}}=17.3$ $\mathrm{kN} / \mathrm{m}^{3}$ at $\mathrm{w}_{\mathrm{OMC}}=17.8 \%$.

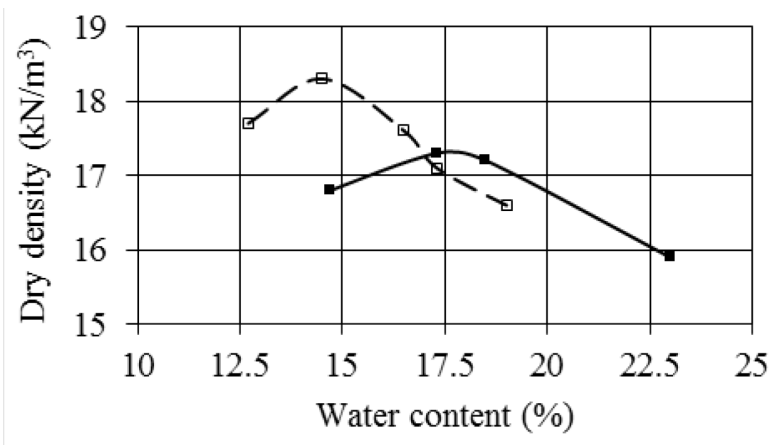

$\longrightarrow-$ Untreated soil $\longrightarrow-2,5 \%$ lime treated soil

Figure 1. Standard Proctor compaction curves of untreated and $2.5 \%$ Proviacal ${ }^{\circledR}$ DD-treated soil from Marche-les-Dames (Bel.

\subsection{Experimental erosion control apparatus}

The EFA device (Figs 2, 3) was developed in the beginning of the nineties in order to measure the erodibility of soils and to predict bridge piers scour (Briaud et al. 1999, 2001).

It is used with site or reconstituted soils and provides a relation between the erosion rate and shear stress (erosion plot) which is called erosion function. In our study, the mixtures tested are poured and compacted in a Shelby tube $(76.2 \mathrm{~mm}$ diameter, ASTM-D1587). The tube is then placed through a circular opening at the bottom of a rectangular cross section conduit $(101.6 \mathrm{~mm} \times 50.8 \mathrm{~mm})$, which is $1.22 \mathrm{~m}$ long. A leak proof connection is obtained thanks to a snug fit and an O-ring. An initial velocity is chosen for the water flow into the conduit and 1 millimeter of soil is extruded into the conduit (Figure 3). The time required for the $1 \mathrm{~mm}$ of soil to erode is then recorded.

When the $1 \mathrm{~mm}$ of soil is eroded or after 30 minutes of flow whichever comes first, the sample at the end of Shelby tube is again cut flush with the bottom of the rectangular pipe, the velocity is increased and the soil is brought back to a $1 \mathrm{~mm}$ protrusion. This procedure is repeated for several values of the flow rate, up to $6 \mathrm{~m} / \mathrm{s}$ if necessary depending on the soil type.

Erosion can occur in different ways, by detachment of individual grains for sandy soils or displacement of entire plates for some silty or clayey soils. Cavities may be formed on the soil surface, resulting in a rather irregular surface, and are then taken into account for estimating the eroded thickness ( $1 \mathrm{~mm}$ equivalent thickness).

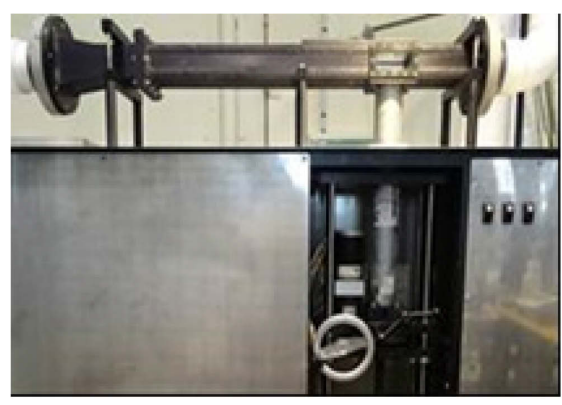

Figure 2. The EFA apparatus of ESTP Paris

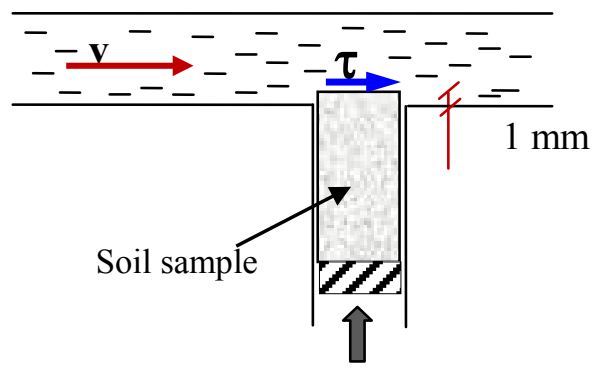

Figure 3. Soil protrusion in the flow pipe of EFA apparatus 


\subsection{Sample preparation}

The soil is first moistened to a water content slightly above $\mathrm{w}_{\mathrm{OMC}}$ that must match a final dry density corresponding to $95 \%$ of the Standard Proctor Optimum. Then it is kept in a sealed bag at $20^{\circ} \mathrm{C}$. After 24 hours, an amount of about $2500 \mathrm{~g}$ is mixed during 3 minutes with 2,5\% lime in order to prepare 3 samples of soil for erosion testing. Soil particles size is manually reduced to about $5 \mathrm{~mm}$ prior to compaction. 3 samples were prepared individually, one after the other. The amount corresponding to one sample is introduced into the Shelby tube in which is disposed first a thin plastic sheet $(0.1 \mathrm{~mm}$ thick $)$ with the aim of preventing the treated soil from sticking to the walls of the tube and to enable an easy removal. The soil is then submitted to a dynamic compaction in order to match the density corresponding to 95\% of Standard Proctor optimum. The soil sample, of about $5 \mathrm{~cm}$, is then removed from Shelby tube, packed in a plastic film with a tape to hold the water content constant during storage in a room at $20^{\circ} \mathrm{C}$ for the required time before the EFA erosion testing (1 day, 7 days, 28 days).

\section{RESULTS AND DISCUSSION}

Each erosion test is performed with a new sample, which is required by the need to respect the curing time. The tests were performed in one day each with about 7 different flow rates applied increasingly.

For each case (untreated soil or $2.5 \%$ lime treated soil at 1,7 and 28 curing days), the tests were repeated 3 times. It is not very easy to choose exactly the same flow rate for different tests and in order to show the results, we have retained almost all the time on erosion curves, all the points corresponding to 3 tests in the same diagram. For example, the results of the first two tests shown in Figures 4 and 5 for the untreated soil will be grouped in a single diagram.

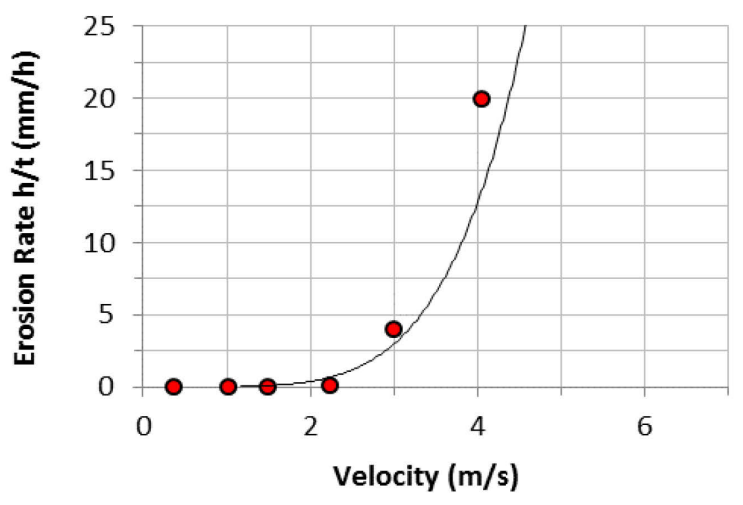

Figure 4. Erosion Rate vs Velocity for untreated soil - Test Nb1

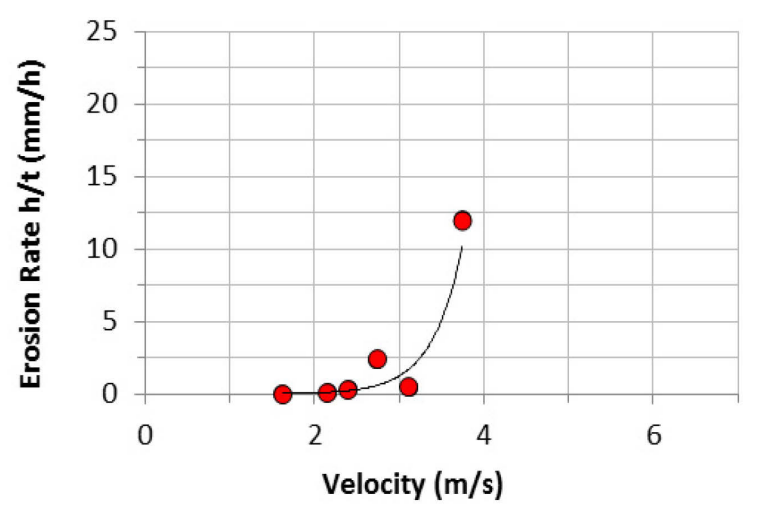

Figure 5. Erosion Rate vs Velocity for untreated soil - Test Nb2

These figures show a form of the erosion function quite comparable, even if the flow rates chosen are not exactly the same. The erosion rate determined with EFA erodimeter will be plotted as a function of the water flow velocity and as a function of the shear stress at the soil-water interface.

We will use three main parameters to compare the different results: the critical shear stress $\tau_{\mathrm{c}}$, which is the stress threshold from which erosion starts, the slope $S_{i}$ of the erosion curve that indicates how fast the soil erodes and the erodibility class according to the classification used for EFA erodimeter testing.

For the four cases studied (untreated soil and soil treated with 1, 7 and 28 curing days), figures 6 to 9 respectively give the curves of the erosion rate as a function of the flow velocity and those of the rate of erosion as a function of shear stress. The results concerning untreated soil and soil treated after 1 curing day are presented together. This is also the case of results for the treated soil after 7 days and after 28 days of curing days which are presented on the same graphics. This presentation was chosen because of similarities of results between on one hand the untreated soil and the soil treated after 1 day of cure and the other between the treated soil after 7 days and 28 days of treatment.

An important observation can be made from the start: on these curves, the axis scale of the erosion rate is not the same in all cases. While for the untreated soil and soil treated with 1 day curing time, the values of erosion rates reach values in the range of 20 to $25 \mathrm{~mm} / \mathrm{hr}$, for soils treated with 7 and 28 days of curing time, the erosion rate hardly exceeds 0.2 to $0.3 \mathrm{~mm} / \mathrm{hr}$.

It can be mentioned that for erosion testing of the untreated soil, there is a particular result that we have not represented in the graphs. This is the value of the erosion rate, $700 \mathrm{~mm} / \mathrm{hr}$, obtained with a flow velocity of $5.5 \mathrm{~m} / \mathrm{s}$. This point, even with a very high erosion rate, is in the area of "medium erodability" in the classification of EFA erosion testing.

On all the curves of Figures 6 to 9, points on the horizontal axis of the graphs are actually points 
where the erosion rate, even if it is not actually zero, does not exceed $0.1 \mathrm{~mm} / \mathrm{hr}$.

The erosion control during a test being performed still visually through a window, it is not possible to accurately estimate values of less than $0.1 \mathrm{~mm} / \mathrm{hr}$. In figure 6 , the intersection of the trend line with the axis of flow velocities gives the velocity threshold, which is of the order of $2.5 \mathrm{~m} / \mathrm{s}$, while in Figure 7, the intersection of the trendline with the axis of the shear stresses provide the critical shear stress (15 $\mathrm{Pa})$.

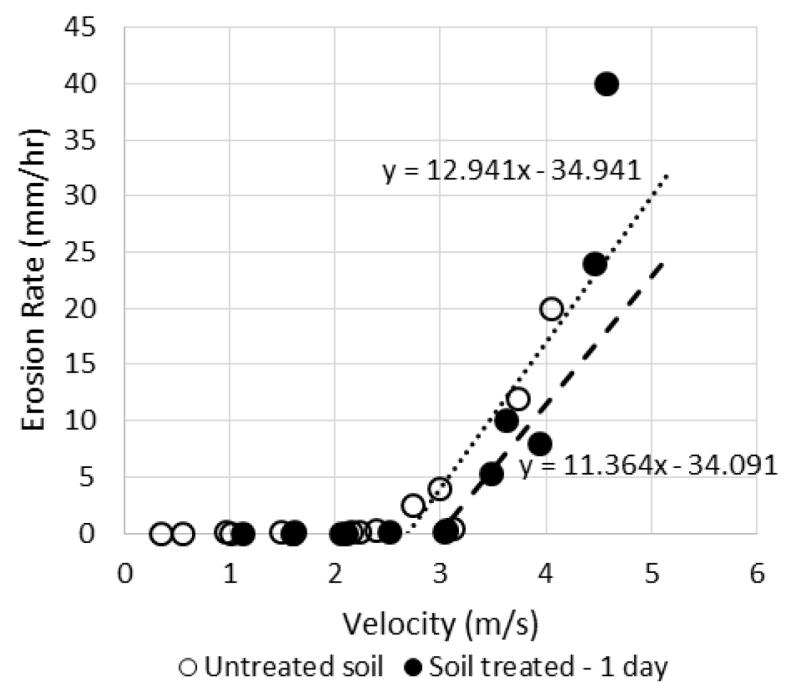

Figure 6. Erosion Rate vs Velocity for untreated soil and soil treated after 1 curing day

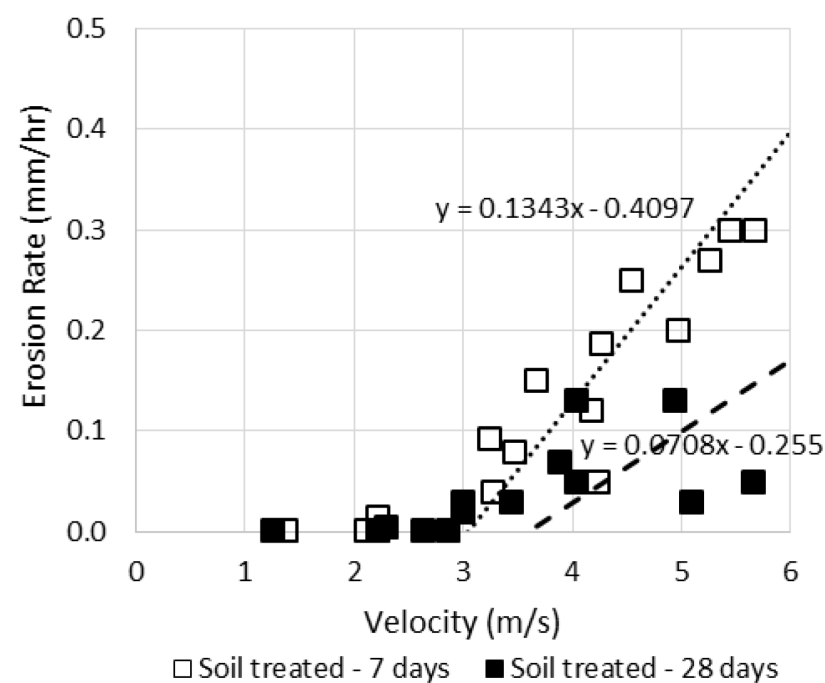

Figure 7. Erosion Rate vs Shear Stress for untreated soil and soil treated after 7 curing days

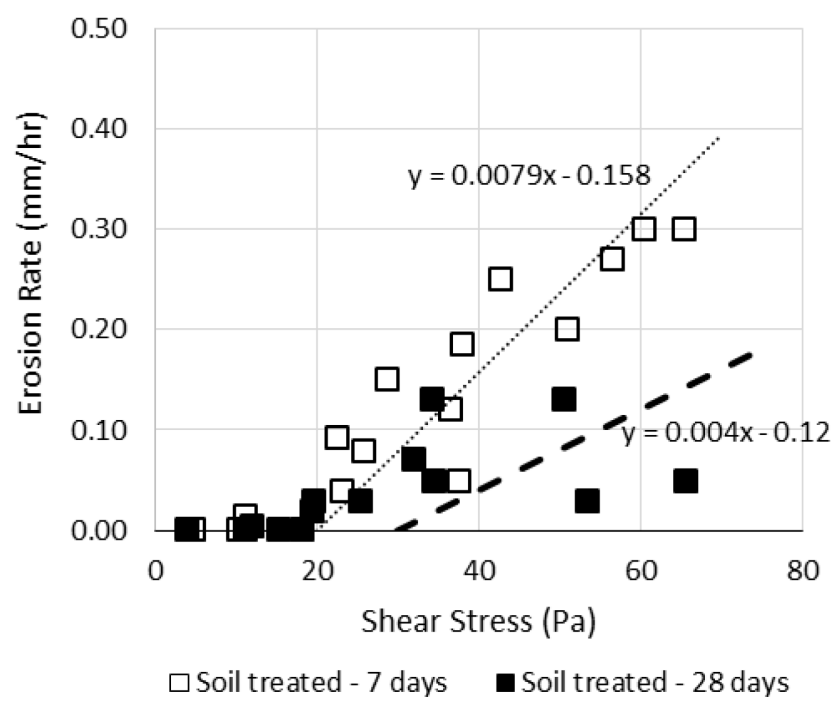

Figure 8. Erosion Rate vs Velocity for treated soil after 7 and 28 curing days

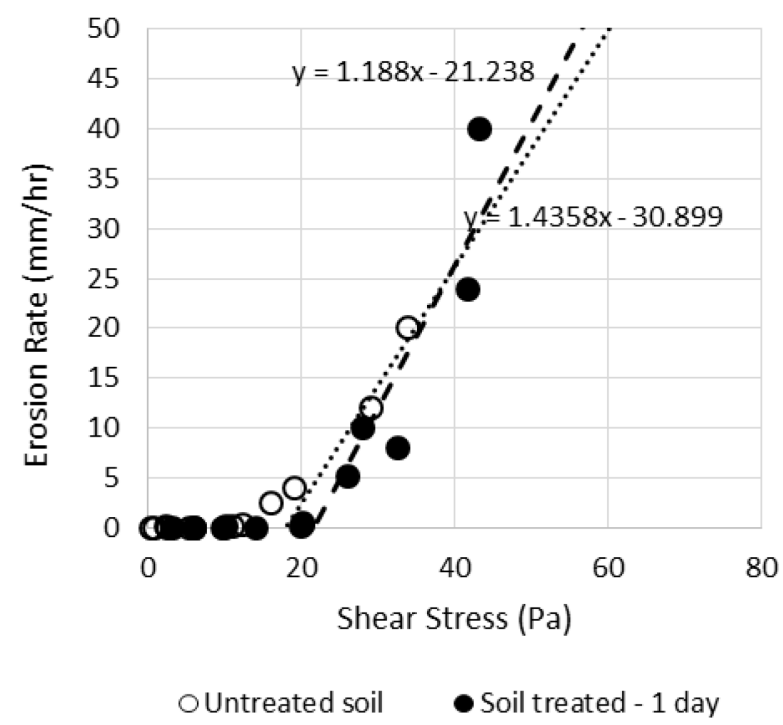

Figure 9. Erosion Rate vs Shear Stress treated soil after 7 and 28 curing days

Table 2 below summarizes the values of critical shear stress and rate of erodibility (slope of the linear interpolation to the erosion curve from the critical stress).

Table 2. Critical shear stress and rate of erodibility for all studied cases

\begin{tabular}{lll}
\hline & $\tau_{\mathrm{c}}(\mathrm{Pa})$ & $\mathrm{S}_{\mathrm{i}}$ \\
\hline Untreated soil & 15 & 1.188 \\
Soil Treated with lime -1 day curing & 20 & 1.436 \\
Soil Treated with lime -7 days curing & 20 & 0.008 \\
Soil Treated with lime -28 days curing & 30 & 0.004 \\
\hline
\end{tabular}


The values in this table show an increase in the critical shear stress with the treatment and curing time (note that $\tau_{c}$ obtained with other types of tests as HET or JET can be very different). The rate of erodability, in turn, is significantly reduced by the treatment.

The value of the critical shear stress for the untreated soil is $15 \mathrm{~Pa}$. This value is higher than that found for a clay of similar plasticity with EFA erosion tests (Robbins \& al. 2011), but remains in the same order of magnitude.

Compared to untreated soil, the critical shear stress of soil treated with 1 and 7 curing days increases of over $30 \%$, from 15 to $20 \mathrm{~Pa}$. This increase is $100 \%$ for soil treated with 28 curing days since the shear stress reached $30 \mathrm{~Pa}$. In the study of Robbins et al. (2011) the lime treatment of similar plasticity clay gave results close to those found in the present study. The critical shear stress increases and the erosion rate decreases with the treatment.

The efficiency of treatment with lime to reduce the erosion rate of Marche-les-Dames soil is also shown in Figure 10. The points shown in this figure correspond to the maximum erosion rate obtained for all test series (in this figure, we considered the result obtained for the untreated soil at $5.5 \mathrm{~m} / \mathrm{s}$ which gave an erosion rate of $700 \mathrm{~mm} / \mathrm{hr}$ ).

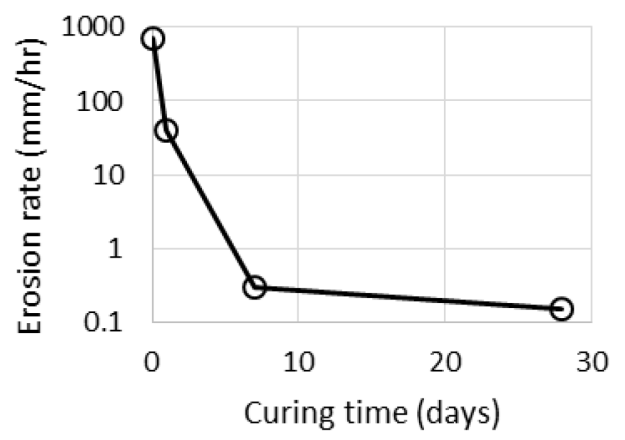

Figure 10. Erosion rate of lime 2.5\% treated Marche-les-Dames soil as function of curing time.

With this $2.5 \%$ lime treatment, the effectiveness was considerably improved, the erosion rate being lowered to $0.3 \mathrm{~mm} / \mathrm{hr}$ and $0.15 \mathrm{~mm} / \mathrm{hr}$ respectively after 7 and 28 curing time.

Figures 11 and 12 include all of the erosion test results as a function of flow rate and as a function of shear stress. These figures clearly show the impact of treatment with $2.5 \%$ lime soil selected for this study. They also show the development of resistance to erosion of the treated soil over time.

Whether this is a function of the flow velocity or the shear stress, the erosion rates obtained classifies the silty soil of Marche-les-Dames in the "Medium Erodability". After treatment and one day of curing time, the critical stress increases a little but the soil remains in the same category of erodibility (Medium Erodability).

From 7 days of curing time, treatment shows quite clear effects. These effects are the spectacular decrease of the rate of erosion, although the critical shear stress does not increase relative to that corresponding to a curing time of 1 day.

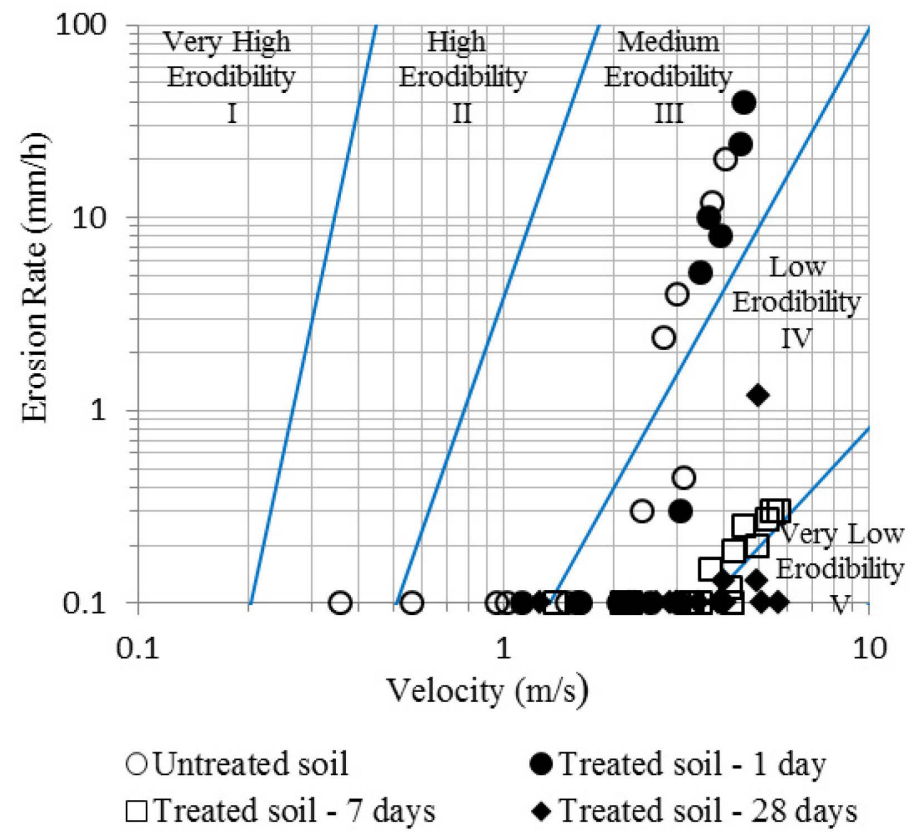

Figure 11. Erosion Rate vs Velocity for untreated soil and 2,5\% lime treated soil with 1,7 and 28 days curing time

The lime addition allows the soil to move from medium erodibility to low erodibility class, 7 days only after treatment. After 28 days curing time, the critical shear stress kept increasing while the rate of erosion kept decreasing. At this stage, the so-valorized silty soil properties ranges at the limit between categories of low and very low erodibility. In addition, the lime treatment leads to an increase of the critical stress.

The lime treated soil can be considered as a cemented material whose particles are assembled thanks to the adhesive forces developed by the lime action. The decrease of erodibility for treated compared to untreated soil can be attributed to the agglomeration and the binding of the particles to each other, which requires higher shear forces to pull them from a surface in contact with a flow. 


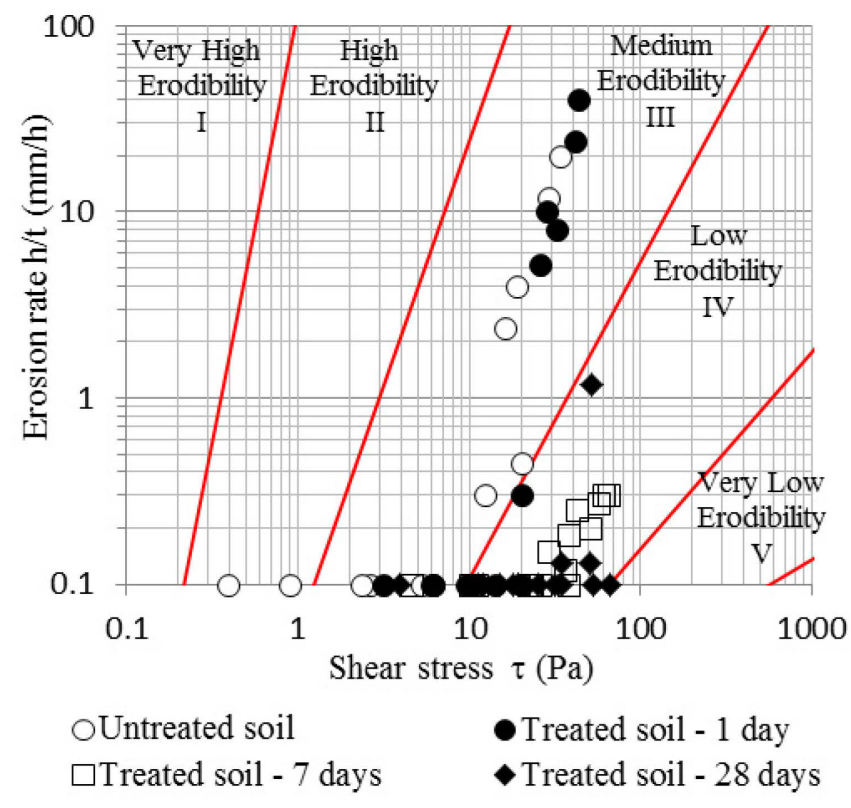

Figure 12. Erosion Rate vs Shear Stress for untreated soil and $2,5 \%$ lime treated soil with 1,7 and 28 days curing time

This increase can primarily be related to the immediate effects of the addition of lime, then to the development of pozzolanic reactions, creating links between soil particles, limiting their detachment. Then it becomes necessary to apply higher hydraulic shear stress to break those bonds and cause detachment of smaller agglomerates or individual particles of soil.

\section{CONCLUSION}

This study was conducted to test the effectiveness of a $2.5 \%$ lime treatment against external erosion, on a silty soil compacted to $95 \%$ of the optimum Proctor. Untreated and treated soil samples after 1, 7 and 28 curing days have been subjected to EFA erosion tests. The main results are:

- The untreated soil erosion rate is fairly high, on the order of $20 \mathrm{~mm} / \mathrm{hr}$ for velocities of up to $4 \mathrm{~m} / \mathrm{s}$ but can reach much higher values for higher velocities: $700 \mathrm{~mm} / \mathrm{hr}$ at $5.5 \mathrm{~m} / \mathrm{s}$. The erosion rate which weakly decreases for the soil treated with 1 day of curing time is considerably reduced at 7 and 28 curing days. - The critical shear stress increases with treatment and curing time $(30 \%$ increase after 1 day of treatment and $100 \%$ after 28 days of treatment).

- According to the classification used in the EFA erodimeter testing, the erodibility is moved from medium erodability zone for untreated soil and soil treated with 1 curing day, at low erodibility ( 7 curing days) or almost very low erodibility (28 curing days). The results highlight an evolutive resistance of lime treated soils with curing time which places them in categories of low to very low erodibility. These results must be compared to earlier findings on the improvement of the internal erosion resistance of the same soil after lime treatment. The same kind of kinetics seems to develop in both cases, with a rapid initial improvement that keeps strengthening with time. Further studies are planned to test the resistance to erosion of soils treated with higher curing times and to find correlations between their erosion resistance and mechanical strength.

\section{REFERENCES}

Awad, I., Yasufuka, N. \& Ochiai, H. 2007. Erosion rates of soils improved by chemical additives for protection against overland flow. Memoirs of Faculty of Engineering, yuchu University, Vol.67, No.4.

Bonelli, S. (coord.) 2012. Erosion of Geomaterials. WileyISTE.

Briaud, L., Ting, K., Chen, C., Gudavalli, R., Perugu, S., Wei, G. 1999. SRICOS: prediction of scour rate in cohesive soils at bridge piers. J.Geotech. Geoenviron. Eng., ASCE 125, 237-24

Briaud, J., Ting, F., Chen, H., Cao, Y., Han, S., \& Kwak, K. 2001. Erosion Function Apparatus for Scour Rate Predictions. Journal of Geotechnical and Geoenvironmental Engineering, 10.1061/(ASCE)1090-0241(2001)127:2(105), $105-113$

Charles, I., . Herrier, G., Chevalier, C., Durand, E., Puiatti, D., Fleureau J.M., Taibi, S., Bonelli, S., Fry, J.J. A real scale experimental dike in lime-treated soil: Evaluation of the methodology, mechanical and hydraulic performance. Proc. of the $7^{\text {th }}$ Conference on Scour and Erosion, Perth, Australia, 2-4 December 2014.

Foster, M., Fell, R. \& Spannagle, M. 2000. The Statistics of Embankment Dam Failures and Accident. Canadian Geotechnical Journal 37, no. 5: 1000-1024.

Herrier, G. \& Bonelli, S. Internal erosion resistance of soils treated with lime: An evolutive benefit. Proc. of the $7^{\text {th }}$ Conference on Scour and Erosion, Perth, Australia, 2-4 December 2014.

Herrier, G., Leconte, P., Nerincx, N., Benelli,S., Mercier, F., Fry, J.J., Tachker, P., Puatti, D. 2014. Lime treatment soil as an erosion-resistant material for hydraulic earthen structures: state of the art and presentation of the french digue.elite project. Proc. of the South Baltic Conference on Dredged Materials in Dike Construction, Rostock, 10-12 April 2014.

Robbins, B., Wibowo, J.L. \& Walshire L.A. 2011. Assessment of improved clay erodibility for overtopping analysis of embankments. USACE Engineering Research and Development Center, Dam Safety Proceedings, September 28, 2011 